\title{
Modal height and modal flavor: The case of Wolof $\boldsymbol{d i}^{1}$ \\ M. Ryan BOCHNAK - University of Konstanz \\ Martina MARTINOVIĆ - University of Florida
}

\begin{abstract}
The Wolof imperfective auxiliary $d i$ is compatible with event-in-progress, habitual and future readings. Furthermore, while varieties of all these readings are available for $d i$ when it sits in a syntactically low position, only future readings are available when it sits in a syntactically high position. We aim to account for this puzzle by combining several ingredients independently motivated in the literature: (i) event-relative circumstantial modality for event-in-progress, habitual, and a subset of future readings; (ii) metaphyisical modality for generalized future readings; (iii) the idea that syntactic height determines the type of modal anchor that projects a modal base. This study contributes to our understanding of the relation between syntactic height and modal flavor, as well as the nature of modal-aspectual interactions cross-linguistically.
\end{abstract}

Keywords: aspect, future, habitual, imperfective, modality, modal flavor, progressive.

\section{The puzzle}

The central puzzle discussed in this paper has two parts, and concerns the verbal auxiliary $d i$ in Wolof (Niger-Congo). First, $d i$ - glossed as 'imperfective' in the descriptive literature ${ }^{2}-$ is associated with several readings (Church, 1981; Robert, 1991): an event-in-progress/progressive reading as in (1); a habitual reading as in (2); and a future reading as in (3). ${ }^{3}$

\author{
Progressive reading; low $\mathrm{di}^{4}$ \\ Dafa di ( $>$ dafay) añ, mën-ul ñëw. \\ do.C.3SG IMPF eat.breakfast can-NEG come \\ 'Il est en train de manger, il ne peut pas venir.' \\ 'He is eating, he cannot come.'
}

(Robert, 1991: p. 263)

(2)

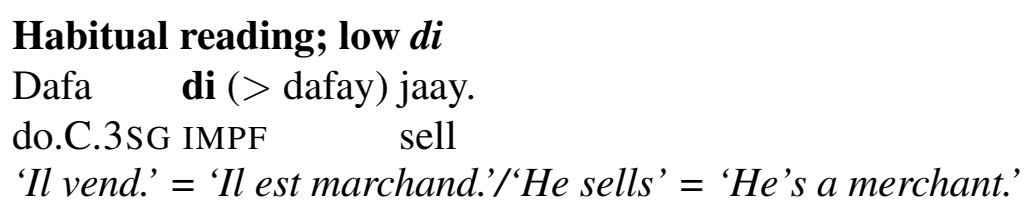

(Robert, 1991: p. 267)

\footnotetext{
${ }^{1}$ We would like to thank our consultants, Jean-Lópold Diouf, Mbaye Diop, Magatte Diop, Abdou Aziz Djakhate, Alioune Kebe, Ismaile Kebe, and Louis Camara. For comments on this work, we are grateful to Ana Arregui, Peter Klecha and Maribel Romero, as well as audiences at the University of Konstanz, Triple A 4 in Gothenburg and SuB in Potsdam. This work was partially supported by an Alexander von Humboldt Fellowship (Bochnak), and by the DFG-funded IGRA Graduate School at the University of Leipzig (Martinović).

2“'Inaccompli" in Church 1981 and Robert 1991; we use the gloss IMPF 'imperfective' in this paper.

${ }^{3}$ Data from Robert 1991 uses translations and context descriptions in French. The English translations are our own. Examples not otherwise marked are from Martinović's fieldwork. The notation Dafa di ( $>$ dafay) invokes the pronunciation whereby $d i$ cliticizes to the previous phonological word as is pronounced $-y$ (IPA [j]) after a vowel-final word.

${ }^{4}$ Abbreviations: $\mathrm{C}=$ complementizer, $\mathrm{CM}=$ class marker, $\mathrm{DEF}=$ definite, $\mathrm{IMPF}=$ imperfective, $\mathrm{INDEF}=$ indefinite, $\mathrm{LCL}=$ locative clitic, $\mathrm{NEG}=$ NEGATION, $\mathrm{PL}=$ plural, $\mathrm{SG}=$ singular .
} 
(3)

\section{Future reading; low $d i$}

Context: devant la maison en construction/in front of a house under construction

Kii mu-a di (> mooy) rafet kër!

this.one $3 \mathrm{SG}-\mathrm{C}$ IMPF be.pretty house

'Elle va être drôlement belle, sa maison, à lui!'/'It's going to be really beautiful, this one's house.'

(Robert, 1991: p. 269)

In comparison, a clause with an eventive verb without $d i$ such as (4) only receives an episodic, default past interpretation. Clauses with stative predicates without $d i$ have a default present reading, as in (5). ${ }^{5}$

(4) Episodic reading with eventive; no di

Xale yi lekk-na-ñu ceeb.

child DEF.PL eat-C-3PL rice

'The children ate rice.'

(5) Present reading with stative; no di

Mbaye bég-na- $\emptyset$.

Mbaye be.happy-C-3SG

'Mbaye is happy.'

The second part of the puzzle is the fact that the availability of these readings depends on $d i$ 's structural position. In (1)-(3), when $d i$ is in its base-generated position in Asp ("low di"), all readings are available. However, when $d i$ is in $\mathrm{C}$ (in non-copular sentences), only the future is possible, as in (6) (Martinović, 2015). The context description (from Robert) indicates that an event-in-progress reading is not possible for "high $d i$ "; we will show later that a habitual reading is also not possible for high $d i$.

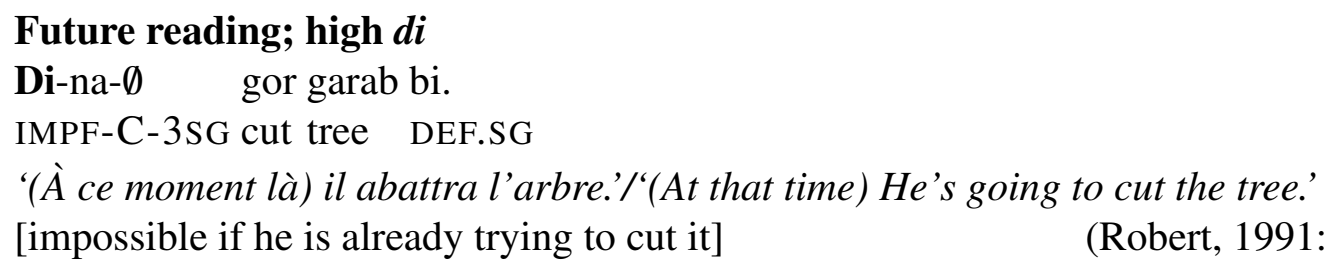

(Robert, 1991: p. 272)

Whereas Robert (1991) took the different readings of $d i$ in the different positions as evidence for two distinct lexical items, in this paper we aim to provide a unified analysis of $d i$ that derives all the attested readings.

In particular, we aim to provide a unified analysis of the readings of $d i$ by combining and expanding on several independently motivated analysis for progressives, habituals, and modality in the literature. First, we follow Portner (1998) and Ferreira (2016) in claiming that eventin-progress and habitual readings crucially involve event-relative circumstantial modality. We

\footnotetext{
${ }^{5}$ Note that Wolof is an optional tense language (Bochnak and Martinović, 2017), but we only show tenseless clauses here (see Smith (1997); Smith and Erbaugh (2005) for an account of default readings of tenseless clauses in other languages).
} 
then extend this idea to cover a subset of future readings, arguing that all readings of low $d i$ can be captured using an event-relative circumstantial modal base. We then argue that future readings for high $d i$ are derived from a metaphysical modal base, following Condoravdi (2002); Kaufmann (2005), and others. Given that the availability of different readings for $d i$ when it is located in different syntactic positions, we argue that this behavior of $d i$ provides new evidence for the idea that modal height correlates with modal flavor, following Hacquard (2010); Kush (2011). Specifically, following Kush (2011), we argue that different modal bases are available at different syntactic heights because of the availability of different types of modal anchors from which a modal base is projected, and that the semantic type of di's complement determines the type of the modal anchor. This work thus contributes to our understanding of the relation between syntactic height and modal flavor, as well as the nature of modal-aspectual interactions cross-linguistically.

The rest of the paper is organized as follows. In section 2 we provide more background on the Wolof language and the syntactic analysis of $d i$ that we assume, and in section 3 we provide more data that corroborate the empirical picture sketched here in the introduction. In section 4 we introduce a proposal for event-in-progress and habitual readings in terms of eventrelative circumstantial modality, following Portner (1998) and Ferreira (2016). In section 5 we sketch how future readings can be incorporated into this view, but also point out its shortcomings, arguing for a metaphysical modal base for future readings of high di. We connect the (un)availability of certain readings for $d i$ with its syntactic position in section 6 , following ideas from Kush (2011). Section 7 concludes.

\title{
2. Background on Wolof and syntax of $d i$
}

Wolof is a Niger-Congo language of the West-Atlantic branch. It is spoken by around 5.2 million people in Senegal, where it is also the lingua franca, and as a minority language in the Gambia and Mauritania (Leclerc 2015). The data in this paper come largely from Martinović's fieldwork in Saint-Louis, Senegal, during 3 trips undertaken between 2014 and 2017.

Wolof finite indicative clauses all have a CP-layer, hosting complementizer-like elements (Dunigan 1994; Martinović 2015). Syntactically, there are two clause-types (Martinović, 2015). The first type is non-wh-movement clauses, where a verbal element necessarily appears in C. This can be the lexical verb, as in (7), the dummy verb def 'do' ${ }^{6}$, exemplified in (8), or the imperfective auxiliary $d i$, shown in (9).

\author{
Main verb in $\mathbf{C}$ \\ Demba tabax-na- $\emptyset$ kër. \\ Demba build-C-3SG house \\ 'Demba built a house.'
}

\author{
'Do' (def) in C \\ Demba daf-a- $\emptyset$ tabax kër. \\ Demba do-C-3Sg build house \\ 'Demba BUILT a house.'
}

\footnotetext{
${ }^{6}$ The $d o$-support clauses express V/VP focus. We use all caps in the translation to indicate this.
} 


\title{
(9) Imperfective auxiliary di in C
}

Demba di-na- $\emptyset$ tabax kër.

Demba IMPF-C-3SG build house

'Demba will/is going to build a house.'

The second clause-type is $w h$-movement clauses in which an element moves to Spec,CP. There is no verbal element in $\mathrm{C}$ in this case.

\author{
Wh-question \\ Lan la Demba tabax? \\ what C Demba build \\ 'What did Demba build?'
}

\section{(11) Relative clause}

kër g-i Demba tabax

house CM-C Demba build

'the house which Demba built'

The imperfective morpheme $d i$ is a verbal head, as evidenced by its syntactic behavior. First, when it is the highest verbal element in the clause, it raises to $\mathrm{C}$ (see (9)). Second, if it is present in the clause, other verbal functional morphology (negation and tense) suffixes onto it, and not onto the lexical verb as shown in (13).

(12) Main verb with negation

Demba daf-a- $\emptyset$ tabax-ul ay kër.

Demba do-C-3SG build-NEG INDEF.PL house

'Demba didn't BUILD houses.'
$D i$ with negation
Demba daf-a- $\emptyset$ d(i)-ul tabax ay kër.
Demba do-C-3SG IMPF-NEG build INDEF.PL house
'Demba won't BUILD houses.'/'Demba isn't BUILDING houses.'/Demba doesn't
BUILD houses.'

Phonologically, $d i$ behaves as a clitic. When there are no suffixes, it forms a phonological unit with the material in $\mathrm{C}$ and pronominal clitics that follow it. In that case, it is pronounced as $\boldsymbol{- y}$, as in (14). ${ }^{7}$

\footnotetext{
${ }^{7}$ Robert (1991) considers $d i$ and $-y$ to be different morphemes. There is good evidence that this is not the correct analysis. For example, in certain situations, like in biclausal progressives, an adjunct can intervene between the imperfective morpheme and the preceding phonological word. When the adjunct is absent the imperfective is pronounced as $-y$, when present, it surfaces as $d i$, shown in (i) and (ii). (See Martinović and Schwarzer (forthcoming) for more on Wolof progressives.)
}
(i) Ma-a-ngi di ( $>$ maangiy) lekk. 1SG-C-LCL IMPF eat
'I am eating.'

(ii) Ma-a-ngi ci tiitange di lekk. 1SG-C-LCL in fear IMPF eat 'I am fearful, eating.' 


\author{
$D i$ as a clitic \\ Demba daf-a- $\emptyset=$ ko di $(>$ koy) tabax. \\ Demba do-C-3SG=it IMPF build \\ 'Demba will BUILD it.'/'Demba is BUILDING it.'/'Demba BUILDS it.'
}

We assume that $d i$ occupies an Asp head below $\mathrm{T}$ (as in (15)), and in clauses with $\mathrm{V}$ in $\mathrm{C}$ raises to $\mathrm{C}$ (in (16)):

(15)

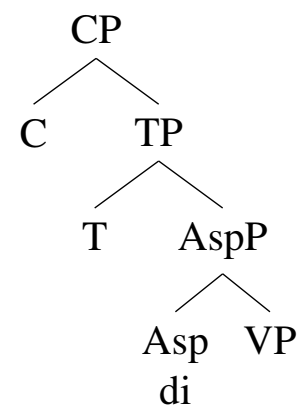

(16)

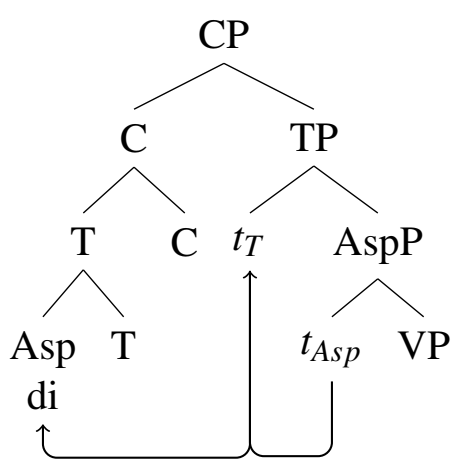

\title{
3. The empirical picture
}

In general, the readings that we have seen are available for all aspectual classes. As we have seen, low $d i$ is compatible with an event-in-progress readings, as in (17). If the event is an achievement, the reading obtained is an iterative one, as in (18).

(17) Low di event-in-progress; accomplishment

[CONTEXT: I am standing in front of a wall with a bucket of paint and I just put a brush to the wall and started drawing something. Someone walks into the room and asks What are you doing? I respond:]

Da-ma di (> damay) rëdd wërëngërël.

do.C-1SG IMPF draw circle

'I am drawing a circle.'

(18) Low di event-in-progress; achievement

[CONTEXT: I hear a repetitive noise from another room, and I ask what that is. Someone answers me:]

Dudu daf-a- $\emptyset$ di ( $>$ dafay) tisooli.

Dudu do-C-3SG IMPF sneeze

'Dudu is sneezing.' 
A habitual reading is also possible when $d i$ is in the low position, as shown in (19) and (20). ${ }^{8}$

\section{Low di habitual; accomplishment}

[CONTEXT: My friend Fatou goes around and draws circles on walls every Monday. Another friend has seen her a few times walking around with a bucket of paint, and asks me what that's about. I tell him:]

Altine b-u nekk, Faatu daf-a- $\emptyset$ di (>dafay) rëdd ay wërëngërël.

Monday CM-C be, Fatou do-C-3SG IMPF draw INDEF.PL circle

'Every Monday, Fatou draws circles.'

\section{(20) Low di habitual; stative}

[CONTEXT: Magatte visits her village rarely, only once every two years, but whenever she goes there, her friend Binta is pregnant. Magatte comments to her mother:]
Binta daf-a- $\emptyset$ di (>dafay) ëmb rekk!

Binta do-C-3SG IMPF be.pregnant only

'Binta is always pregnant!'

Meanwhile, future readings are available for both low and high di. Examples (21) and (22) show this for low $d i$; (23)-(26) show this for high $d i$.

\section{Low di future; accomplishment}

[CONTEXT: I see Mbaye walking around the town with an architect, buying building materials, etc., and I ask our mutual friend what Mbaye is up to, and he tells me:]

Mbaye daf-a- $\emptyset$ di (> dafay) tabax kër.

Mbaye do-C-3SG IMPF build house

'Mbaye is going to build a house.'

\section{(22) Low di future; stative}

[CONTEXT: Fanta and her husband Ibrahim cannot conceive a child, so they go to see a 'doctor' who uses local plants and herbs to make medicine. He gives them a tea and tells Fanta to drink it every day, promising:]

Fanta daf-a- $\emptyset$ di ( $>$ dafay) ëmb.

Fanta do-C-3SG IMPF be.pregnant

'Fanta is going to get pregnant.'

\section{(23) High di future; accomplishment}

[CONTEXT (same as (21)): I see Mbaye walking around the town with an architect, buying building materials, etc., and I ask our mutual friend what Mbaye is up to, and

${ }^{8}$ Generic readings are also possible for low $d i$, as shown in (i). We set aside these readings for the rest of the paper, though we are hopeful they can be accounted for under the analysis we pursue; see Deo 2009 for unifying event-in-progress, habitual, and generic readings of imperfectives.

(i) jant bi, penku la di (>lay) fenke

sun DEF.SG east C IMPF rise

'Le soleil, c'est à' l'est qu'il se lève.'

'The sun, it's in the east that it rises.' (Church, 1981: p. 114) 
he tells me:]

Mbaye di-na- $\emptyset$ tabax kër.

Mbaye IMPF-C-3SG build house

'Mbaye is going to build a house.'

(24) High di future; stative

[CONTEXT: Fatou is making Oussman's favorite dish for lunch and I walk in and say:] Usmaan di-na- $\emptyset$ bég.

Oussman IMPF-C-3SG happy

'Oussman is going to be happy.'

(25) High di future; achievement

[CONTEXT: I am throwing a party and I ask Fatou if anyone from her family will be there. She tells me that her brother Moussa will come:]

Musaa di-na- $\emptyset$ ñëw.

Moussa IMPF-C-3SG come

'Moussa will/is going to come.'

(26) High di future; achievement

[CONTEXT: I am playing a game with Loulou in which we stare into each other's eyes and try not to blink. Ibrahim is watching us and he sees that Loulou's eyes are starting to water and that she is having trouble keeping them open. He says:]

Lulu di-na- $\emptyset$ xef.

Loulou IMPF-C-3SG blink

'Loulou is going to blink.'

Only a future reading is possible for high $d i$. The context for (27) and (28) make an eventin-progress reading or habitual reading plausible, and a future reading implausible. In such a context, speakers reject the use of high $d i$ in (28).

\section{Low di; progressive or habitual}

[CONTEXT: There is a party and Magatte is dancing. Her husband Mbaye does not like it when she dances in public, so he is in a bad mood. A friend asks what is wrong, and Mbaye says:]

Magatte daf-a- $\emptyset$ di ( $>$ dafay) fecc.

Magatte do-C-3SG IMPF dance

'Magatte is dancing.'/'Magatte always dances.'

(28) High di; only future reading

[CONTEXT (same as (27)): There is a party and Magatte is dancing. Her husband Mbaye does not like it when she dances in public, so he is in a bad mood. A friend asks what is wrong, and Mbaye says:]

\#Magatte di-na- $\emptyset$ fecc.

Magatte IMPF-C-3SG dance

'Magatte is going to dance.' 


\begin{tabular}{|c|ccc|}
\hline & event-in-progress & habitual & future \\
\hline low $d i$ & $\checkmark$ & $\checkmark$ & $\checkmark$ \\
\hline high $d i$ & $\#$ & $\#$ & $\checkmark$ \\
\hline
\end{tabular}

Table 1: Readings of low and high $d i$

In sum, when $d i$ is in the low position, it is compatible with event-in-progress, habitual, or future readings. When $d i$ is in the high position, only the future reading is possible. These findings are summarized in Table 1. Our analysis is an attempt to account for these two facts.

\section{Event-in-progress and habitual readings}

It has long been acknowledged in the literature that readings associated with imperfective morphemes incorporate a modal component (Dowty, 1979; Landmann, 1992; Portner, 1998; Deo, 2009; Arregui et al., 2014; Ferreira, 2016). Many of these authors have also explicitly attempted to offer a unified analysis of the several readings associated with imperfective morphology cross-linguistically, especially for event-in-progress and habitual readings. In this section, we introduce Portner's (1998) analysis of the English Progressive, couched within a framework of event-relative modality, and Ferreira's (2016) extension of Portner's analysis for habituals, and map these on to the event-in-progress and habitual readings for (low) di in Wolof.

\subsection{Portner's analysis for event-in-progress}

Following previous analyses by Dowty (1979) and Landmann (1992), Portner (1998) offers a modal analysis of the English Progressive form. The key components of Portner's analysis are the following.

First, in a departure from a classical Kratzerian semantics for modality (Kratzer, 1981, 2012), the modality involved is event-relative, rather than world-relative. That is, a set of modal alternatives is projected from an event of evaluation, rather than a world of evaluation. The modal base for the Progressive operator is a circumstantial one - it consists of the set of worlds $w^{\prime}$ where the circumstances surrounding event $e$ in the evaluation world $w$ also hold. Among the circumstances include properties of the event participants, such as their abilities and dispositions. The modal base is further relativized to an event description $P$. This move is important, since one and the same event may be described in different ways, but the nature of the event description has an effect on whether speakers judge a sentence containing a Progressive as true or false. Compare (29a) and (29b):
a. Alex was swimming westward.
b. Alex was swimming to New York.

Both sentences could in principle be used to describe one and the same event qua set of actions (e.g., Alex jumps into the ocean in Portugal and begins swimming west), but we would generally judge (29b) as false if Alex is a typical human who wouldn't have the ability to swim all the 
way across the Atlantic. The goal PP isn't part of the event description in (29a), and so doesn't figure in to our reasoning for deciding on its truth. An adaptation of Portner's formalization of the modal base is given in (30):

$$
\begin{aligned}
& \text { Event-relative circumstantial modal base: } \\
& \bigcap \operatorname{CIRC}(e, P, t, w) \\
& =\left\{w^{\prime} \mid w^{\prime} \text { is compatible with the circumstances surrounding } e \text { qua } P \text {-event at } t \text { in } w\right\}
\end{aligned}
$$

Second, in line with a Kratzerian analysis of modality, Portner makes use of an ordering source that further restricts the quantification over the modal base. For the Progressive, the ordering source is a set of propositions that represent the "set of outside factors that need to go right" (Portner, 1998: p.773) for the event in progress at the reference time to be completed. It is the set of propositions that entail that $e$ qua $P$-event does not get interrupted, as in (31).

$$
\begin{aligned}
& \text { Non-interruption ordering source: } \\
& \mathrm{NI}(e, P, t, w)=\{p \mid p \text { entails that } e \text { qua } P \text {-event in } w \text { does not get interrupted after } t\}
\end{aligned}
$$

The propositions in NI serve to order the worlds in CIRC. Worlds where more of the propositions in NI are true are better worlds than those where fewer propositions in NI are true. The idea is that the Progressive does not quantify over the entire modal base, but only a subset of the modal base which is ranked "best" or ideal according to the ordering source. We adapt Portner's definition of BEST in (32), where $w^{\prime \prime}<_{\mathrm{NI}} w^{\prime}$ means that $w^{\prime \prime}$ is ranked better than $w^{\prime}$ according to the ordering source NI:

$$
\operatorname{BEST}(\mathrm{CIRC}, \mathrm{NI}, w)=\left\{w^{\prime} \text { in } \bigcap \mathrm{CIRC} \mid \neg \exists w^{\prime \prime} \text { in } \bigcap \text { CIRC where } w^{\prime \prime}<_{\mathrm{NI}} w^{\prime}\right\}
$$

The Progressive universally quantifies over the set of worlds in BEST, and those worlds (the "inertia" worlds) are those where a $P$-event is actually completed.

Finally, there is a temporal component to the Progressive, namely that the reference time be a non-final subinterval of the run time of the event that is completed in the inertia worlds. In other words, the event $e$ ongoing at the reference time $t$ is a temporal subevent of a $P$-event $e^{\prime}$, whose temporal trace is a superset of and extends into the future of $t$.

Putting these pieces together, a Portner-style semantics for the Progressive can be modeled as in (33), where $P$ is a property of events, $\tau$ is the temporal trace function, and $t \subset_{n f i n} t^{\prime}$ means that $t$ is a non-final subinterval of $t^{\prime}$.

$$
\begin{gathered}
\llbracket \mathrm{PROG} \rrbracket=\lambda P_{\langle v, s t\rangle} \lambda t \lambda w \cdot \exists e\left[t \subseteq \tau ( e ) \& \forall w ^ { \prime } \in \operatorname { B E S T } ( \mathrm { CIRC } , \mathrm { NI } , w ) \left[\exists e ^ { \prime } \exists t ^ { \prime } \left[t \subset_{n f i n} t^{\prime}\right.\right.\right. \\
\left.\left.\left.\left.\& t^{\prime}=\tau\left(e^{\prime}\right) \& P\left(e^{\prime}, w^{\prime}\right)\right]\right]\right] \quad \text { (= preliminary analysis of } \llbracket d i_{(\text {low })} \rrbracket\right)
\end{gathered}
$$

This analysis accounts for the possible non-actualization of a $P$-event in the actual world. Although the actual world will be located in the circumstantial modal base, it might not be among the set BEST according to the ordering source (i.e., if the event gets interrupted). 
Let us propose that the event-in-progress reading for Wolof $d i$ can be modeled using (33). The sentence (17), repeated here as (34), is given the truth conditions in (35), assuming a modal base and ordering source along the lines of (35a) and (35b). ${ }^{9}$

$$
\begin{aligned}
& \text { Da-ma di ( }>\text { damay) rëdd wërëngërël. } \\
& \text { do.C-1SG IMPF draw circle } \\
& \text { 'I am drawing a circle.' }
\end{aligned}
$$

$$
\begin{aligned}
& \llbracket \text { damay rëdd wërëngërë } l \rrbracket \\
& =\lambda w . \exists e \exists t\left[t \subseteq \tau ( e ) \& \forall w ^ { \prime } \in \operatorname { B E S T } ( \mathrm { CIRC } , \mathrm { NI } , w ) \left[\exists e ^ { \prime } \exists t ^ { \prime } \left[t \subset_{n f i n} t^{\prime} \& t^{\prime}=\tau\left(e^{\prime}\right)\right.\right.\right. \\
& \left.\left.\left.\quad \& \operatorname{draw}\left(s p, c, e^{\prime}, w^{\prime}\right)\right]\right]\right] \\
& \text { a. } \quad \mathrm{CIRC}(e, P, t, w)=\{\text { 'The speaker intends to draw a circle', 'The speaker knows } \\
& \text { how to draw a circle', 'The speaker is paying attention to the task',...\} } \\
& \text { b. } \quad \mathrm{NI}(e, P, t, w):\{\text { 'The speaker's paintbrush doesn't break', 'The speaker doesn't run } \\
& \quad \text { out of paint', 'The speaker doesn't get distracted', } . .\}
\end{aligned}
$$

Summing up, the key ingredients of a Portner-style analysis of event-in-progress readings are an event-relative modal base (and ordering source), together with a forward-shifting temporal component (i.e., the runtime of a $P$-event extends into the future of the reference time in the inertia worlds).

\subsection{Habitual readings}

It is widely known that imperfectives in many languages are compatible with both event-inprogress and habitual readings (among others), and several proposals in the recent literature have emerged to make sense of this fact under a unified analysis of imperfectivity (Arregui et al. 2014; Cipria and Roberts 2000; Deo 2009; Ferreira 2016, among others). In this paper we will follow Ferreira (2016), since it is a recent analysis that explicitly and minimally extends Portner's analysis of the Progressive for habitual readings as well.

Ferreira aims to give a generalized meaning for imperfective morphology to account for the event-in-progress/habitual syncretism found in many languages. He argues that Portner's analysis for event-in-progress readings can be carried over straightforwardly to habitual readings as well, with one important innovation: event plurality. Specifically, Ferreira argues that the imperfective can apply to singular or plural events. When the imperfective applies to a singular event, the event-in-progress reading obtains; when applied to plural events, the imperfective yields a habitual reading.

On this view, the VP denotes a set of events, to which singular and plural event operators can apply, returning sets of singular and plural events, respectively. These operators apply at the VP level below Asp, and are defined in (36):

$$
\text { a. } \quad \operatorname{SG}(\llbracket \mathrm{VP} \rrbracket)=\left\{e_{1}, e_{2}, e_{3}, \ldots\right\}
$$

\footnotetext{
${ }^{9}$ For simplicity, we assume the reference time variable is existentially bound in a tenseless clause.
} 
b. $\quad \operatorname{PL}(\llbracket \mathrm{VP} \rrbracket)=\left\{e_{1} \oplus e_{2}, e_{2} \oplus e_{3}, e_{1} \oplus e_{3}, e_{1} \oplus e_{2} \oplus e_{3}, \ldots\right\}$

We can maintain the semantics for $d i$ following the denotation in (33), assuming that it applies not to VP directly, but to VP plus a singular or plural operator. When the singular operator applies, the event-in-progress reading obtains, as in (35). ${ }^{10}$ When the plural operator applies, the habitual reading obtains. Our analysis for the habitual sentence (19), repeated as (37), is given in (38):

(Altine b-u nekk,) Faatu daf-a- $\emptyset$ di ( $>$ dafay) rëdd ay wërëngërël. Monday CM-C be, Fatou do-C-3SG IMPF draw INDEF.PL circle '(Every Monday,) Fatou draws circles.'

$$
\begin{aligned}
& \llbracket \text { Faatu dafay rëdd ay wërëngërël } \rrbracket \\
& =\lambda w . \exists e \exists t\left[t \subseteq \tau ( e ) \& \forall w ^ { \prime } \in \operatorname { B E S T } ( \mathrm { CIRC } , \mathrm { NI } , e ) \left[\exists e ^ { \prime } \exists t ^ { \prime } \left[t \subset_{n f} t^{\prime} \& t^{\prime}=\tau\left(e^{\prime}\right)\right.\right.\right. \\
& \left.\left.\left.\quad \& \operatorname{PL}\left(\mathbf{d r a w}\left(f, c, e^{\prime}, w^{\prime}\right)\right)\right]\right]\right]
\end{aligned}
$$

For such a habitual sentence to be true, a single $P$-event need not be ongoing at $t$, but the run-time of a habit (a plurality of events) must be ongoing at $t$.

\section{Future readings of $d i$}

In this section, we seek to extend the analysis for event-in-progress and habitual readings of $d i$ to future readings. We first explore whether the semantics we already have is enough to account for these readings, and we will see that there are problems. We then consider the possibility that future readings (for high $d i$ ) make use of a metaphysical modal base instead.

\subsection{Circumstances are not enough}

While futures are in general typically analyzed as involving modality, future readings are not usually taken to involve circumstantial modality, but something else: either metaphysical (see Condoravdi, 2002; Copley, 2002, 2008; Kaufmann, 2005) or epistemic (see Giannakidou and Mari, 2018).

There is, however, a variety of futures that might plausibly be analyzed as involving circumstantial modality. These are the futurate readings of the present tense (with Progressive or non-Progressive aspect) in English (Copley, 2002, 2008).

(39) The Red Sox \{play/are playing $\}$ the Yankees tomorrow.

(40) \#The Red Sox $\{$ defeat/are defeating $\}$ the Yankees tomorrow.

As Copley and others have pointed out, these readings require that some kind of plan or schedule be available in the context. (40) is thus odd since it suggests that the game is fixed.

\footnotetext{
${ }^{10}$ Instead of the conjunct $\operatorname{draw}\left(s p, c, e^{\prime}, w^{\prime}\right)$ in $(35)$, we have $\operatorname{SG}\left(\operatorname{draw}\left(s p, c, e^{\prime}, w^{\prime}\right)\right)$.
} 
Copley argues for a modal semantics of futurates that involves the following ingredients. First, such sentences (i) presuppose that there is some director $d$ who is able to "direct" the prejacent proposition $p$, and (ii) assert that $d$ is committed to bringing about that $p$ in the worlds quantified over. Copley argues that futurates involve a metaphysical modal base with a bouletic ordering source. However, it seems intuitively plausible that a circumstantial modal base with noninterruption ordering source could also get these facts. We have already seen in (29) that dispositions and abilities of the event participants can be part of the circumstances of an event from which a modal base can be projected for event-in-progress readings (and Ferreira (2016) shows this to be true for habituals as well). If we can include a plan for a future event as part of the circumstances that hold at the reference time, then in principle the semantics we have already developed for $d i$ should be able to derive future readings as well.

The analysis for a sentence like (21), repeated here as (41), would look something along the lines of (42), where the event $e$ that is ongoing at the reference time is the planning event, and $e^{\prime}$ is a temporal superevent that includes the planning event and the event of actually building the house.

(41) [CONTEXT: I see Mbaye walking around the town with an architect, buying building materials, etc., and I ask our mutual friend what Mbaye is up to, and he tells me:]

Mbaye daf-a- $\emptyset$ di ( $>$ dafay) tabax kër.

Mbaye do-C-3SG IMPF build house

'Mbaye is going to build a house.'

$$
\begin{aligned}
& \lambda w . \exists e \exists t\left[t \subseteq \tau ( e ) \& \forall w ^ { \prime } \in \operatorname { B E S T } ( \mathrm { CIRC } , \mathrm { NI } , e ) \left[\exists e ^ { \prime } \exists t ^ { \prime } \left[t \subset_{n f} t^{\prime} \& t^{\prime}=\tau\left(e^{\prime}\right)\right.\right.\right. \\
& \left.\left.\left.\quad \& \operatorname{SG}\left(\text { build.a.house }\left(m, e^{\prime}, w^{\prime}\right)\right)\right]\right]\right]
\end{aligned}
$$

Such an analysis does seem on track for the examples we have collected so far where a future reading is available for low di. In (22), for instance (see section 3), the relevant circumstances would be the fact that the doctor has prescribed the medicine and that Fanta plans to take it. ${ }^{11}$

However, this analysis will not derive all the future readings available for sentences with $d i$. In particular, there are several examples with high $d i$ which seem to simply involve a prediction, and a relation to any planning event seems tenuous at best, for instance (24) and (26) in section 3. It would seem, then, that not all future readings for high $d i$ can be accounted for using a circumstantial modal base.

\subsection{Another modal base for future readings of high $d i$}

Following a Kratzerian view on modals (Kratzer, 1981, 2012), different modal flavors for one and the same modal is due not to ambiguity, but to the availability of different modal bases. Thus, epistemic and deontic must have the same lexical entry, but the different readings are due

\footnotetext{
${ }^{11} \mathrm{~A}$ reviewer for $\mathrm{SuB}$ asks whether we have independent motivation for the idea that planning or preparatory events can be targeted by grammatical operators in Wolof. We have not yet been able to adduce such evidence from the data at our disposal.
} 
to the availability of different sorts of modal bases (epistemic and circumstantial, respectively). Since our semantics for $d i$ makes use of a modal base and ordering source, we can extend the idea of having different modal bases available for $d i$ as well. ${ }^{12}$

Now, we have just seen that a circumstantial modal base won't derive the future readings for (high) $d i$ that don't seem to involve any sort of planning or preparatory event. Other authors have treated future readings as involving either metaphysical or epistemic modality. For Condoravdi (2002); Copley (2002, 2008); Kaufmann (2005) and others, futures involve a metaphysical modal base with intertial or bouletic ordering sources. For Giannakidou and Mari (2018), apparent 'futures' in Italian and Greek are always epistemic, but can receive their future temporal orientation from a non-past tense scoping under the modal.

In Wolof, we find that $d i$ cannot have an epistemic reading. In the context of (43), the modal mën is used instead. ${ }^{13}$

[CONTEXT: Loulou and I are expecting our friend Magatte and someone knocks.]

a. \#Di-na- $\emptyset$ nekk Magatte.

IMPF-C-3SG be Magatte

intended: 'That will be Magatte.'

b. Mën-na- $\emptyset$ nekk Magatte.

can-C-3SG be Magatte

'That could be Magatte.'

In the absence of evidence for epistemic uses of $d i$, we will stick to the more standard view that futures are metaphysical. We will follow the idea that a metaphysical modal base consists of the set of possible futures branching from an evaluation time $t$ (Condoravdi, 2002; Kaufmann, 2005; Klecha, 2016). The future orientation of a metaphysical modal base is derived via the Diversity Condition (Condoravdi, 2002), which requires that a modal base contain worlds where the prejacent (embedded) proposition is true and worlds where the prejacent is false. This condition derives future temporal orientation, since the past is already 'settled'. We take a metaphysical modal base to be anchored to world-time pairs, as in (44) (cf. Kush 2011; Klecha 2016).

$$
\begin{aligned}
& \text { METAPHYSICAL MODAL BASE: } \\
& \bigcap \text { METAPH }(<w, t>)=\left\{w^{\prime} \mid w^{\prime} \text { is identical to } w \text { up to time } t\right\}
\end{aligned}
$$

We will assume a stereotypical intertial ordering source; cf. Copley (2002, 2008), where the ordering source for futures can also be bouletic. Putting these pieces together, a preliminary semantics for the future readings of (high) $d i$ can be modeled as in (45), where $P$ is now a

\footnotetext{
${ }^{12}$ Arregui et al. (2014) also make use of different types of modal bases to derive the variability in the interpretation of imperfectives in several languages.

${ }^{13}$ Further examples of this kind should be tested. For instance, Winans (2016) shows that there are interpretational differences in English between the two types of epistemic statements using will:

(i) a. That will be the neighbors barbecuing.

b. The neighbors will be barbecuing.
} 
property of times. A preliminary analysis of (25), repeated below as (46), is then given in (47).

$$
\begin{aligned}
& \text { Preliminary proposal for future readings of di: } \\
& \llbracket d i_{h i g h} \rrbracket=\lambda P_{\langle i, s t\rangle} \lambda t \lambda w . \forall w^{\prime} \in \operatorname{BEST}(\operatorname{METAPH}, \operatorname{STER}, t, w)\left[\exists t^{\prime}>t\left[P\left(t^{\prime}, w^{\prime}\right)\right]\right]
\end{aligned}
$$

Musaa di-na- $\emptyset$ ñëw.

Moussa IMPF-C-3SG come

'Moussa will/is going to come.'

$$
\lambda w . \exists t\left[\forall w^{\prime} \in \operatorname{BEST}(\operatorname{METAPH}, \operatorname{STER}, t, w)\left[\exists e \exists t^{\prime}\left[t^{\prime}>t \& t^{\prime} \circ \tau(e) \& \operatorname{come}\left(m, e, w^{\prime}\right)\right]\right]\right]
$$

A couple of comments are in order before we continue. First, we assume that when di takes a metaphysical modal base, the event variable is existentially closed. Second, we assume that the metaphysical readings for futures subsume the circumstantial ones, i.e., futures where there is a planning or preparatory event ongoing at the reference time are compatible with a metaphysical modal base as well, so we don't rule out the compatibility of circumstantial futures with (45). Finally, we note that the future temporal profile of $d i$ is derived in two different ways, comparing (45) with (33). We discuss this issue more in the next section, after detailing our proposal for connecting modal flavor with the syntactic position of $d i$.

\section{Modal variability and syntactic height}

Taking stock of where we have come, we have proposed that the different readings for $d i$ are derived by different types of modal bases. The event-in-progress and habitual readings, as well as future readings involving a planning or preparatory event, are derived by a circumstantial modal base anchored to an event. The other future readings involve a metaphysical modal base anchored to a world-time pair. Recall as well that the availability of these readings depends on the syntactic position where $d i$ appears in the clause. For low $d i$, the readings available are those derived from a circumstantial modal base. For high $d i$, the only reading available is the future reading, based on a metaphysical modal base. The remaining work, then, is to correlate the choice of modal base for $d i$ with its syntactic position, which will in turn derive the desired readings for $d i$ in the two positions.

The availability of certain readings depending on syntactic height is reminiscent of the generalization that epistemic and root modality correlate with modals occupying high and low positions, respectively (e.g., Cinque 1999; Hacquard 2006, 2010; Kush 2011). Under Hacquard's analysis, low-scoping modals (below T) necessarily take a circumstantial modal base, and high-scoping modals (above $\mathrm{T}$ ) necessarily take an epistemic modal base. We too derive the readings for low $d i$ via a circumstantial modal base. If we follow Hacquard closely, the modal base would be epistemic for high di. We have already argued against having an epistemic modal base for high $d i$, and settled on a metaphysical modal base to derive the future readings of high $d i$.

We propose the following. Low $d i$ is located in Asp, where only a circumstantial modal base is available. High $d i$, in contrast, moves to its high position via $\mathrm{T}$, where it has access to a 
metaphysical modal base. The structural aspect of our proposal is sketched in (48)-(49).

$$
\text { CIRC modal base }
$$

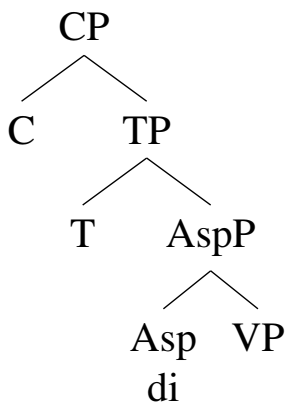

$$
\text { METAPH modal base }
$$

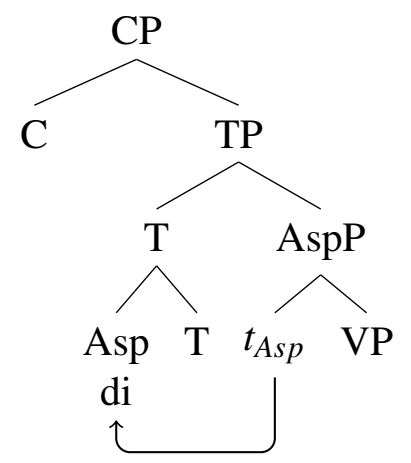

The mechanics of the proposal are as follows. The choice of modal base for di not only correlates with syntactic height, but also with the semantic type of $d i$ 's complement. When $d i$ is in Asp, its complement (VP) is type $\langle v, s t\rangle$. When $d i$ is in T, its complement (AspP) is type $\langle i, s t\rangle$. This type difference in turn determines the type of modal anchor available to derive the modal base. In Asp, the modal anchor available to $d i$ is an event, which projects a circumstantial modal base (cf. Portner 1998; Hacquard 2010); in T, the modal anchor available to $d i$ is a world-time pair, which projects a metaphysical modal base (cf. Kush 2011).

Our final proposal for the semantics of $d i$ in its different positions is as follows in (50):

$$
\begin{aligned}
& \text { When } P \text { is eventive: } \\
& \begin{array}{l}
\llbracket d i_{\text {low }} \rrbracket=\lambda P_{\langle v, s t\rangle} \lambda t \lambda w . \exists e\left[t \subseteq \tau ( e ) \& \forall w ^ { \prime } \in \operatorname { B E S T } ( \mathrm { CIRC } , \mathrm { NI } , w ) \left[\exists e ^ { \prime } \exists t ^ { \prime } \left[t \subset_{n f \text { in }} t^{\prime}\right.\right.\right. \\
\left.\left.\left.\qquad \& t^{\prime}=\tau\left(e^{\prime}\right) \& P\left(e^{\prime}, w^{\prime}\right)\right]\right]\right]
\end{array}
\end{aligned}
$$

When $P$ is temporal:

$$
\llbracket d i_{h i g h} \rrbracket=\lambda P_{\langle i, s t\rangle} \lambda t \lambda w . \forall w^{\prime} \in \operatorname{BEST}(\operatorname{METAPH}, \text { STER }, t, w)\left[\exists t^{\prime}>t\left[P\left(t^{\prime}, w^{\prime}\right)\right]\right]
$$

Although our analysis is disjunctive, the readings that are (un)available for $d i$ are still derived in a systematic way. The lexical entries don't make direct reference to the syntactic position of $d i$, but rather depend on the semantic type of its complement. ${ }^{14}$

One issue that remains in deriving a truly unified analysis for all uses of $d i$ lies in the temporal component. Although both entries for $d i$ in (50) have a future-oriented temporal interpretation, the ways in which this is derived is different for high and low $d i$. For high $d i$, there is a direct future-shifting meaning incorporated into its semantics: there is a time $t^{\prime}$ in the future of the reference time $t$ of the clause. For low $d i$, the future orientation is a bit more indirect. An event $e^{\prime}$ takes place over the interval $t^{\prime}$, which is a superinterval of the reference time $t$. Since it is specified that $t$ be a non-final subinterval of $t^{\prime}$, it follows that a part of $t^{\prime}$ continues into the future of $t$. It is thus only the culmination of $e^{\prime}$ that is guaranteed to be in the future of $t .{ }^{15}$

\footnotetext{
${ }^{14}$ If we assume a temporal variable located in the T head (cf. Bochnak and Martinović 2017), then given the tree in (49), the order of the first two arguments for $d i$ when $P$ is temporal should be reversed, with the semantic type for $d i$ in this case being $\langle i,\langle\langle i, s t\rangle, s t\rangle\rangle$.

${ }^{15}$ Recall that in the case of circumstantial futures, $e^{\prime}$ includes preparatory stages ongoing at the reference time.
} 
Given the connection we have proposed between the type of modal anchor and the semantic type of the modal operator's complement (following Kush 2011), we can ask how an epistemic modal base would be derived in such a system. Kush (2011) proposes that an epistemic modal base is projected from a world anchor, which is available when a modal has a complement of type $\langle s, t\rangle$, i.e., when a modal is located higher than T. ${ }^{16}$ If this idea is on the right track, the natural question is why (high) $d i$ cannot take on an epistemic modal flavor, given that it appears in $\mathrm{C}$ after moving through $\mathrm{T}$ (see (16)), where it presumably has a complement of type $\langle s, t\rangle$.

We make the following speculations. First, there could be a lexical specification in $d i$ that it cannot take an epistemic modal base. Although many modals (in English and other languages) can take a variety of modal bases to take on a variety of modal flavors, certain modals are lexically restricted to certain flavors. For example, the German modal dürfen is restricted to deontic interpretations in the indicative mood. So it could be that $d i$ is restricted to circumstantial and metaphysical modal bases. This would be a stipulation, but would rule out epistemic modal bases for $d i$. Second, it could be that something about the temporal/aspectual profile of $d i$ is incompatible with an epistemic modal base. For instance, certain authors have argued that there is no future epistemic readings for English must (Werner, 2006). However, Giannakidou and Mari (2018) argue for future epistemic readings in Greek and Italian, and Winans (2016) offers the following example as a future reading of epistemic must in English:

John must leave tomorrow, the train only leaves once a month and it is tomorrow.

Thus, it is not clear that there is some deep incompatibility between futurity and epistemic modality that would independently rule out epistemic interpretations for $d i$. We leave a more principled investigation into why $d i$ cannot take on epistemic readings for future research.

Another remaining question has to do with the correlation of syntactic height and modal flavor. On our analysis, low $d i$ has the readings it does because it sits in Asp, and only has access to a circumstantial modal base projected from an event. Meanwhile, high di moves through $\mathrm{T}$ and receives its metaphysical modal base in that position. However, given the analysis in section 2 based on Martinović (2015), di continues to move up to C. We have speculated why $d i$ cannot receive an epistemic modal base in the $\mathrm{C}$ position, but another question remains. If high $d i$ can pick up its modal base in $\mathrm{T}$ before moving on to $\mathrm{C}$, why can it not pick up a circumstantial modal base in Asp before moving on to $\mathrm{T}$ and $\mathrm{C}$ ? In other words, what rules out the progressive and habitual readings for high $d i$ in our analysis? There are a couple directions one could take to address this question. First, there could be a general principle at work such that $d i$ must receive its modal base in the highest position possible, while independently ruling out taking on an epistemic modal base in $\mathrm{C}$. We know of no independent motivation for such an analysis. Second, perhaps di receives a metaphysical modal base in $\mathrm{C}$ after all, and not in $\mathrm{T}$. The mechanics of such an analysis remain to be worked out, but if a world-time pair anchor for a metaphysical modal base were available when $d i$ is in $\mathrm{C}$, then this would take care of at least part of this issue. For now, we must leave the spelling out of these suggestions for future research.

\footnotetext{
${ }^{16}$ Compare Hacquard (2010), where all modal bases are projected from events.
} 


\section{Conclusions}

To sum up our analysis of the puzzle we introduced at the beginning, we correlate the available readings for Wolof $d i$ with its syntactic height. For low $d i$ in Asp, the modal base is anchored by an event, deriving a circumstantial modal base and Portner/Ferreira semantics for progressives and habituals, and circumstantial future readings. For high $d i$ in $\mathrm{T}$, the modal base is anchored by a world-time pair and is metaphysical, and only a future interpretation is derived. The choice of modal base depends on type of modal anchor, which depends on semantic type of di's complement.

Our analysis offers a new cross-linguistic perspective on the way modal height determines modal flavor via different types of modal anchors. We have departed from Hacquard (2010) in not claiming that all modal bases are projected from events, but the analysis we propose is along the same spirit, in that objects other than worlds can project a modal base. This case study from Wolof furthermore contributes to our understanding of the modal ingredients of aspectual operators, and more generally of the interactions between aspect, modality and temporality in natural language.

\section{References}

Arregui, A., M. L. Rivero, and A. Salavona (2014). Cross-linguistic variation in imperfectivity. Natural Language and Linguistic Theory 32, 307-362.

Bochnak, M. R. and M. Martinović (2017). Optional past tense in Wolof. Talk presented at Annual Conference on African Linguistics 48, Indiana University.

Church, E. (1981). Le système verbal du wolof. Université de Dakar, Documents Linguistiques. Cinque, G. (1999). Adverbs and Functional Heads. New York: Oxford University Press.

Cipria, A. and C. Roberts (2000). Spanish imperfecto and preterito: Truth conditions and Aktionsart effects in a situation semantics. Natural Language Semantics 8, 297-347.

Condoravdi, C. (2002). Temporal interpretation of modals: Modals for the present and for the past. In D. Beaver, L. Casillas Martínez, B. Clark, and S. Kaufmann (Eds.), The construction of meaning, pp. 59-87. Stanford, CA: CSLI Publications.

Copley, B. (2002). The Semantics of the Future. Ph. D. thesis, Massachusetts Institute of Technology, Cambridge, MA.

Copley, B. (2008). The plan's the thing: Deconstructing futurate meanings. Linguistic Inquiry 39(2), 261-274.

Deo, A. (2009). Unifying the imperfective and the progressive: partitions as quantificational domains. Linguistics and Philosophy 32, 475-521.

Dowty, D. (1979). Word meaning and Montague Grammar. Dordrecht: Reidel.

Dunigan, M. B. (1994). On the clausal structure of Wolof. Ph. D. thesis, University of North Carolina at Chapel Hill, Chapel Hill, NC.

Ferreira, M. (2016). The semantic ingredients of imperfectivity in progressives, habituals, and counterfactuals. Natural Language Semantics 24(4), 353-397.

Giannakidou, A. and A. Mari (2018). A unified analysis of the future as epistemic modality: The view from Greek and Italian. Natural Language and Linguistic Theory 31(1), 85-129.

Hacquard, V. (2006). Aspects of Modality. Ph. D. thesis, Massachusetts Institute of Technology, 
Cambridge, MA.

Hacquard, V. (2010). On the event relativity of modal auxiliaries. Natural Language Semantics 18, 79-114.

Kaufmann, S. (2005). Conditional truth and future reference. Journal of Semantics 22(3), 231-280.

Klecha, P. (2016). Modality and embedded temporal operators. Semantics and Pragmatics 9(Article 9), 1-55.

Kratzer, A. (1981). The notional category of modality. In H.-J. Eikmeyer and H. Rieser (Eds.), Words, worlds, and contexts: New approaches to word semantics, pp. 163-201. Berlin: Walter der Gruyter.

Kratzer, A. (2012). Modals and Conditionals: New and Revised Perspectives. New York: Oxford University Press.

Kush, D. (2011). Height-relative determination of (non-root) modal flavor: Evidence from Hindi. In Proceedings of SALT 21, pp. 412-425.

Landmann, F. (1992). The progressive. Natural Language Semantics 1, 1-32.

Leclerc, J. (2015). Lamnagement linguistique dans le monde. http://www.axl.cefan. ulaval.ca/afrique/senegal.htm.

Martinović, M. (2015). Feature Geometry and Head-Splitting: Evidence from the Morphosyntax of the Wolof Clausal Periphery. Ph. D. thesis, University of Chicago, Chicago, IL.

Martinović, M. and M.-L. Schwarzer (Forthcoming). Locatives and biclausal progressives in Wolof. In Proceedings of the 48th Annual Meeting of the North East Linguistic Society.

Portner, P. (1998). The progressive in modal semantics. Language 74(4), 760-787.

Robert, S. (1991). Approche énonciative du système verbale: le cas due wolof. Paris: Editions du CNRS.

Smith, C. (1997). The Parameter of Aspect. Dordrecht: Kluwer.

Smith, C. and M. Erbaugh (2005). Temporal interpretation in Mandarin Chinese. Linguistics 43(4), 713-756.

Werner, T. (2006). Future and non-future modal sentences. Natural Language Semantics 14, $235-255$.

Winans, L. (2016). Inferences of will. Ph. D. thesis, University of California Los Angeles, Los Angeles. 